\title{
Between Cultures and Generations: Ethnic Activism of 1.5 Generation Immigrant Leaders
}

\author{
Rachel Sharaby ${ }^{1}$ \\ Ashkelon Academic College, Israel
}

\begin{abstract}
This article discusses ethnic activism in advancing a religious holiday in the absorbing society among 1.5 generation social-political activists who immigrated to Israel from Ethiopia. The findings show that syncretism was created in the identity, and in the organization and leadership patterns of the Ethiopian leaders that reflected their goals. By displaying symbols of their ethnic identity, they struggled over the right of their excluded minority group to ethnic otherness and its inclusion in the collective space. They stressed the importance of these ethnic celebrations as a factor that unifies the people and the symmetry of this unity. They served as a bridge between generations, between tradition and modernity, and between the absorbing and the absorbed. The article supplies essential insights on how young leaders use their ethnic tradition as a resource for the recruitment of cultural, social, and political capital for uniting a minority group and integrating it into society.
\end{abstract}

Keywords: 1.5 generation, holiday, identity, immigrants, leadership, syncretism.

Israeli society is a society of immigrants who arrived in waves from different countries and communities worldwide, including Ethiopia (Reichman, 2009), who are the subject of this article. This article comprises part of a comprehensive study that investigated the ritual dynamics of the Sigd, a religious holiday of Ethiopian immigrants in Israel, from a multigenerational perspective, including elderly spiritual leaders (Sharaby, 2020a) and the youth of this community (Sharaby, 2020b). This article focuses on social-political leaders of the 1.5 generation who expressed a cultural merging of protest and integration utilizing this ethnic celebration.

In the sociological discourse on international immigration, the 1.5 generation is defined as youth who immigrated with their parents and comprised an intermediary generation, between the parents' generation and the second and third generation, as detailed below. The 1.5 generation construct has become common in immigration studies investigating cultural patterns among the children of immigrants. The uniqueness of the present article rests in a discussion on the 1.5 generation leadership that has, to date, not received attention in the research literature on immigration. Furthermore, contrary to the children of other minority groups of immigrants in Israel, members of the 1.5 generation of immigrants from Ethiopia experienced transition difficulties that originated not only in their cultural difference, but also due to their skin color and the doubt that was cast on the Judaism of their ethnic group.

The Jews of Ethiopia were cut off from the rest of the Jewish People since the destruction of the First Temple. Their customs are therefore not compatible with the halakha (Jewish oral tradition) of the religious Jewish world (Shalom, 2012). They upheld customs that were not

Correspondent Author E-Mail: rsharaby@gmail.com ${ }^{1}$ 
customary in other Jewish communities, where the most important of these was the Sigd holiday, which is a pilgrimage holiday they celebrated on November 29 , on high mountains. This is a day of fasting, purification, and prayer, during which the religious priests (the kessoch, singular - kess) read portions of the Torah and prayed for a return to the Land of Israel (Shalom, 2012). The schedule of the Sigd, similarly to any ritual activity, was fixed and accompanied by symbols.

The kessoch were the main symbols in the ritual system of the Sigd and conducted all of its stages: they prepared their communities for the Sigd; purified the mountain; ascended it at the head of the celebrators' procession according to a hierarchical order; conducted the religious ritual; descended the mountain at the head of the procession; and fulfilled a central role in the collective holiday meal (Ben-Dor, 1985).

In the 1970s, the political conditions in Israel and Ethiopia enabled the immigration of the Jews to Israel via Sudan (Ben-Ezer, 2010). The journey on foot was wrought with hardships: hunger and thirst, attacks by robbers, rape, and death. The harsh conditions in the transition camps in Sudan caused great mortality and the breakup of families and communities (Ben-Ezer, 2010; Sharaby \& Kaplan, 2014). The Ethiopians immigrated to Israel in two waves: Operation Moses in 1984 and Operation Solomon in 1991 (Spector, 2005).

According to the Central Bureau of Statistics (2019), the Ethiopian community in Israel at the end of 2018 included 151,800 people, which comprise 1.7\% of the total Israeli population, where approximately $43 \%$ of them were born in Israel. Even today, this is a hamstrung population, whose opportunities in education and occupation remain limited. The Ethiopian immigrants cope with absorption difficulties originating in their skin color and cultural difference and experience discrimination and marginalization (Ben Simon et al., 2019; Elia-Leib et al., 2018).

The controversy over their Judaism also served as a cause for their exclusion. Because of concern for intermarriage, first wave immigrants were required to undergo conversion to be registered as Jews and receive Israeli citizenship. After a prolonged protest, the religious establishment withdrew from its position, and a national registrar was appointed to examine the couple's Judaism when registering for marriage (Corinaldi, 2005). The doubting of the immigrants' Judaism severely harmed the status of their spiritual leaders. After a struggle, the religious establishment recognized them in the early 1990s, and they receive (partial) wages from the religious councils. However, they have limited authority (Sharaby \& Kaplan, 2014).

The young generation of immigrants who arrived from Ethiopia with their parents were trapped between different values systems and experienced value conflicts. They felt dual alienation, both from their parents and from their peer group in the absorbing society (Saka et al., 2012). The intercultural gaps created different intergenerational perceptions and conflicts regarding the family hierarchy, which redefined the relationships between the children and their parents. The difficulties that the youth experienced within the family system and without influenced the complexity of their ethnic identity (Anteby-Yemini, 2002; Engdaw-Vanda, 2019; Shmuel, 2017; Honegger, 2020).

As a preliminary discussion on the complex identity of the leaders of the 1.5 generation of immigrants from Ethiopia, I will begin with a review of the relevant literature that served as the basis for the present study: structuration of the ethnic identity of the 1.5 generation during situations of immigration, as well as the syncretism model for analysis of ethnic revitalization processes and shaping of a multidimensional identity in the postmodern age, where encounters take place within the framework of global immigration. 


\section{Ethnic Identity of the 1.5 Generation}

The ethnic identity of immigrants is one of the main issues in the sociology of immigration (Barbera, 2015). Ethnic identity is a personal perception set constructed by the absorbing society in the process of everyday interactions between immigrants and veterans. It is a multidimensional phenomenon and is reflected on different levels (Kim, 2011; Prashizky \& Remennick, 2018; Remennick, 2003).

The internal-personal dimension of the identity usually motivates the individual and is reflected, as expected, in external aspects of identification. The construct of identification expresses the set of ways and means by which individuals actually externalize their sense of identity by expressing attitudes and performing measurable defined acts (Della Pergola, S, 2016). The selfidentity as a member of a group, a sense of belonging and commitment to the group, positive (or negative) attitudes toward the group, a sense of shared attitudes and values, specific ethnic elements such as language and customs are all characteristics of the ethnic identity and identification (Ben Rafael \& Peres, 2000).

Contrary to the past, today immigrants are usually not required to suppress aspects of their identity in order to become assimilated into the majority group. Thanks to adopting a multicultural policy in most Western countries, immigrants have found ways to contain their diverse identities simultaneously and use them in different social contexts (Hodzi, 2019; Lehman \& Welch, 2020; Levitt \& Glick-Schiller, 2004; Morales \& Bardo, 2020; Vertovec, 2001).

The process of ethnic identity construction is dynamic and changes according to the period and the immigration target. An immigrant's ethnic identity is constructed by the absorbing society, which ascribes him or her to a particular social group in the proximal host society, simultaneously creating changes in an immigrant's attitudes toward himself (Lev-Ari, 2010; McCorkle, 2020; Portes \& Rumbaut, 2001). An immigrant's encounters with new people, institutions, and spaces create opportunities to re-examine his identity (Liebkind, 2006). This is a process of the social construction of ethnic identity and boundaries, which is a product of the negotiation of immigrant groups with each other and with the rest of society (Kibria, 2000; Stroup, 2017).

Research on immigrants usually distinguishes between first-generation immigrants and their children. The first generation comprises parents who left the country of origin and settled in a new country. The second generation includes those who immigrated when they were up to eight years old or were born in the new society. It was found that among immigrants to America, many assimilate quite well in their adoption of the general American identity. However, many also identify with the traditions of their country of origin in certain events and according to convenience (Park, 2008; Portes \& Rumbaut, 2001). For example, the dual identity adopted by secondgeneration Asian immigrants in the United States enabled them to identify with the Asian heritage, and concomitantly to consider themselves as part of American society (Park, 2008). Similar conclusions were reached by researchers who investigated identities of second-generation immigrants in the multi-ethnic reality in the United States (Alba \& Waters, 2011) and in NorthWest Europe (Slootman, 2019).

Members of the 1.5 generation are those who immigrated as older children (from age eight and up) or as adolescents. They arouse research interest because they were educated and underwent socialization in the country of origin and experience a particularly strong intercultural conflict in their identity (Lev-Ari, 2010; Remennick \& Prashizky, 2018). Extreme responses characterize the absorption of the 1.5 generation.

Research on the 1.5 generation has become increasingly common in European and American studies that investigated cultural patterns and wellbeing among immigrants' children 
(Costigan et al., 2009; Roberge, 2002). The construct of the "1.5 generation" was also examined in researches on different ethnic groups which immigrated to Israel: from the Former Soviet Union (Prashizky \& Remennick, 2017), South Africa (Costigan, 2015), Kurdistan and North Africa (Sharaby, 2018).

Researches indicate that the absorption of members of the 1.5 generation may be more problematic than that of members of the second generation (Lev-Ari, 2012; Min \& Kim, 2000; Remennick \& Prashizky, 2018). They are characterized by radical responses: some may resolve their identity conflict by increasing their efforts for assimilation, acquiring an education and social mobility, while others may exhibit resistance to speaking the language of the absorbing society and adopting its values. Some even develop at-risk youth behaviors, including dropping out of school, violence, and delinquency (Portes \& Rumbaut, 2001; Zhou \& Bankston, 1998). Ethnic counteractivity has been observed among young immigrants from minority groups in Western countries, whose physical "visibility" exposed them to discrimination (Sharaby \& Kaplan, 2014).

\section{Cultural Syncretism}

The construct of syncretism means a mixing and merging of religious and cultural beliefs, customs, and practices, and the creation of a new tradition (Mayaram, 2012; Stewart \& Shaw, 1994). This construct usually refers to a synthesis of religious forms, as part of an integration between religions or different traditions within the same religion (Leopold \& Jensen, 2004; Walter et al., 2019). However, it is not possible to isolate religious fusion from the social and cultural aspects, because adherence to a religion is an integral part of social behavior. In addition, what may seem to be a religious act at a particular time and place, may be viewed as a cultural activity in another time and place (Stewart \& Shaw, 1994).

The construct of syncretism refers to cultural and social changes in general. Scholars use it to describe the inclusion of traditions in different fields, such as language, art, philosophy or medicine. Processes of religious and cultural syncretism took place in antiquity and in the modern age, where colonial cultures dominated the local cultures. Syncretism is also an important component in the global era (Mayaram, 2012).

Syncretism indicates a change in the personal or group identity as well as the conformations of this process. It is part of the negotiation between identities under different situations, such as under occupation, commerce, immigration, religious dissemination, and ethnic marriage. Religious and cultural syncretism can be created consciously and formally, but sometimes evolves unconsciously and unintentionally (Leopold \& Jensen, 2004; Paganoni, 2003).

Identifying a ritual or a tradition as syncretic helps us follow the history that shapes religions and cultures and understand that they have complex origins and are reconstructed through a process of selection and synthesis (Bronner \& Shulman, 2020; Keefer \& Haj-Broussard, 2020; Koepping, 1994), which involves processing, interpretation, adaptation of traditional symbols and customs to the new culture, and adoption of foreign contents. The outcome is a dual and sometimes even multiple identity that contributes to the preservation of the ethnic identity, to meaningful intergenerational communication in the immigrant family, and to continuity of the tradition in modern society.

The theoretical contribution of the syncretism model, as opposed to other immigration theories such as multicultural assimilation (Sharaby, 2015), is that it focuses on the change among the immigrants and not the hosts. The syncretism model shows that the process can be two-way (Croucher \& Kramer, 2017; Stewart \& Shaw, 1994). Change transpires in the cultural values of majority/modern/host groups (syncretism from the top). The outcome is compromise, cultural 
diversity, and a modification of its cultural and religious repertoire.

Nevertheless, cultural and religious fusion is created mainly in the lives and ceremonies of the weaker group - the minority/traditional/immigrant group (syncretism from the bottom), with variations of tradition and modernity (Sharaby, 2002). This pattern represents resistance to different forms of control, an expression of identity, and a strategy for social and cultural negotiation (Anoegrajekti et al. 2018; Purkayastha, 2005; Yigit \& Tarman, 2016; Zhang et al., 2018).

\section{The Research Goal and Methodology}

This article suggests another theoretical model for the 1.5 generation, a bipolar identity of simultaneous integration and protest. It turns attention to the leaders of the 1.5 generation of immigrants who have not been highlighted in research to date. The issue of leadership, through its consolidation and influence, has been discussed in the research literature (Bass, 2009). The leadership phenomenon is consolidated through three major components: the led, the environmental context, and the leader (Maccoby, 2009).

Researchers emphasized the characteristics and traits of leaders, such as personal charisma, the ability to create a vision and hope, persons with values (Popper, 2002; Weber, 1979). However, more and more studies show that the led group and the circumstances (the context) have significant weight in consolidating leadership. Studies emphasize the group's need for a leader, particularly during times of crisis (Oliver-Lumerman et al., 2018; Popper \& Maysless, 2003; Ramsey \& Ricket, 2020). The cultural context is critical in the consolidation of the leadership figure (Hofstede \& Hofstede, 2010). Leadership is particularly significant during periods of uncertainty and weakening of formal authority (Popper, 2007).

Recent research deals in the broader spectrum of social leaders in private and public organizations, and recently also in leaders of nonprofit organizations and social movements. Leadership is no longer perceived as a set of unique abilities and characteristics of the single person, but rather as an action that obligates partnerships, ideology, and strategy that takes place within dynamic social systems (Oliver-Lumerman et al., 2018).

In recent years, under the influence of cultural and global changes, studies are also performed on "intercultural leadership," leadership that includes those led from different cultures and normative systems. An intercultural leader can bridge cultural differences among his led (Collard, 2007; Oliver-Lumerman et al., 2018).

It is my contention that syncretism, which means the mixing of religious and cultural elements, was created in the identity and behavior of social-political leaders of the 1.5 generation of immigrants from Ethiopia. The syncretism that occurred in Sigd celebrations in Israel and its mobility toward the cultural center was initiated by the 1.5 generation leaders of the immigrants from Ethiopia. They aspired, via a selective return to their ethnic roots, to create a renewed syncretic Sigd that would advance their goal of connecting the holiday to audiences from their community and outside. These leaders can be regarded as "initiators of identity" (Eisenstadt, 2013, p. 427), due to the ethnic activism they expressed. They not only protested against the discrimination of their ethnic group, but also acted to introduce its cultural symbols into the public domain.

This study examines, based on the declarations and actions of the 1.5 generation leaders of the immigrants from Ethiopia, how they succeeded in taking a holiday that does not have an essentially entertaining nature, that represented an ethnic group whose Judaism was doubted, and establishing it in Israel: what relevant meanings they afforded the holiday and what syncretism was created, i.e., which traditional characteristics remained and which Israeli ones were adopted. 
This study focused on four prominent social-political leaders, who have an academic education, and emigrated from Ethiopia in the 1980s at the age of 10-19. They, therefore, fall under the sociological definition of the 1.5 generation. They headed organizations that acted for advancing immigrants from Ethiopia, initiated and led the Sigd holidays in collaboration with and funding from national institutions and other organizations of immigrants from Ethiopia, and struggled to achieve national recognition of this holiday.

This research combined different methods. First, a content analysis was performed on articles in the Israeli press from the late 1980s. There were few reports. They are brief and comprise an allegory to the marginal status of the Sigd and this ethnic group. A major source for this study was the newspaper Yedioth Negat (in Hebrew and Amharic), which has been published in Israel since 1999 by the Steering Center for Ethiopian Immigrants in the Education System. The newspaper published in November is always dedicated to the Sigd and includes extensive coverage of the holiday events and numerous interviews with organizers of the holiday celebrations, members of the 1.5 generation. The testimonies and articles clearly present the dilemmas faced by the community, which accompanied the evolution of the Sigd. The organizers' tendency to include all members of the community in the celebrations, and to turn the Sigd into an Israeli holiday, is also apparent. The headings are also self-evident: "Everyone's Holiday"; "To Connect the Younger Generation"; "A Holiday for All Jews"; "To Open to Society"; "Who are We, Really"; "The Sigd, a National Holiday in Israel"; "A Return to Roots" and more.

Pana Lapid - Journal of the Israel Association of Ethiopian Jews was also used. This journal is not published regularly and has a smaller distribution, but publishes essential information on the Sigd. Additional sources were pamphlets published by Ethiopian organizations as well as Internet sites.

The written sources were complemented with several participatory observations of Sigd celebrations in Jerusalem by the researcher. The first observation occurred in 2006. This was a robust anthropological experience and motivated collecting additional primary materials and writing of this paper. Several semi-structured in-depth interviews were held with two leaders of the 1.5 generation, in 2002 and 2006, who were both around age 40 at the time of the interviews.

The phenomenological-hermeneutical method utilized attributes importance to understanding, describing, and analyzing a social phenomenon through the participants' subjective experience (van Mannen, 2011). A semi-structured in-depth interview can supply information and focuses on references to the issue that a researcher has chosen. However, a researcher also allows the interviewee to express himself or herself and develop topics in unforeseen directions. A researcher must clarify and interpret the perceptions of the participants regarding the meaning of the studied phenomenon (Sabar Ben-Yehoshua, 2016).

\section{Findings}

\section{Initial Shaping of the Celebration}

The first Sigd celebrations in Israel were characterized by a search for the way and tensions among the Ethiopian Jews regarding the shaping of the holiday in the early 1980s (Abbink, 1983). The kessoch, who were stripped of their authorities by the religious establishment, were also pushed aside from their status of conducting the Sigd ritual. Conversely, Rabbi Menahem Malek, who was the Chief Rabbi of the immigrants from Ethiopia, and young activists, played a dominant role in consolidating the Sigd program, which deviated from the traditional pattern. For example, they supported holding a single Sigd celebration in order to turn it into a major event for the 
Ethiopian Jews (Josephsberg Ben-Yehoshua, 2013), avoided including the kessoch in the early planning stages of the celebration, shortened the kessoch's prayers, and added new contents, such as a prayer by the Chief Rabbi of Israel (Abbink, 1983). It seems that the purpose of these changes was both to adapt the Sigd to the new society and to placate the religious establishment and achieve approval for their ethnic holiday and Judaism, which had been doubted.

In the late 1980s, against the background of the mass immigration from Ethiopia, the Beta Israel Organization was founded on the initiative of youth activists of the community. Moshe Yamano, head of the organization, emigrated to Israel as a youth in 1977 and, therefore, meets the definition of 1.5 generation. He said (in an interview, 2006), that the organization that operated until the late 1980s was intended to absorb the immigrants preserve their tradition, and organize the celebrations. Moshe and members of the Beta Israel Organization also organized the protest of the Ethiopian immigrants against the religious establishment in 1985, with a demand to recognize them as Jews.

Because of the secrecy of the immigration wave, government agents asked members of the community not to celebrate the Sigd to avoid media attention. However, Moshe Yamano and his friends insisted on celebrating the Sigd, and many participants arrived (Ben-Dor, 1985). This achievement stressed the power of the community's young activists and their determination to continue the ritual tradition.

Because the organization of the Sigd was led by activists of the community, who conducted a battle against the establishment due to its demand for their conversion, Rabbi Menahem Malak, a representative of the rabbinical establishment, was diverted from his role in conducting the Sigd. The Beta Israel Organization afforded a more significant role in the celebrations to the traditional leaders of the community. According to Moshe Yamano, the organizers also acquiesced to the kessoch and held a stricter traditional ritual. However, because the Sigd was moved to a different social context, changes took place, indeed moderate ones during these years, and new elements were adopted (Bar-Yuda, 1990; Kipper, 1989).

\section{Fixed and Political Ritual}

In the late 1980s, the Jewish Agency established the Israel Association of Ethiopian Jews and supported its activities, including the organization of the Sigd. Mula Kasai, who headed this organization, immigrated from Ethiopia in 1980, at the age of 19, and, therefore, meets the definition of the 1.5 generation. He served as an absorption coordinator of the General Organization of Workers in Israel and was sent to Ethiopia in 1991 to help in immigrant absorption. He also served as the first Ethiopian member of the Israeli parliament (the Knesset) in the 1990s. These sources gave the impression that in the Sigd ritual, the organization that Mula headed conducted a fixed and more political ritual that was consolidated from the 1990s, and included both traditional and modern elements (Cesana, 1995; Yedioth Aharonoth, 1995; Maharat, 1999).

Masses of people arrived at the Government House promenade that overlooks the Temple Mount where the Temple stood, from the early morning hours. Estimates suggest that between 20 to 30 thousand participants arrived every year from 2005-2007, including people who did not belong to the Ethiopian community (Adamaso, 2005). Many celebrators came by organized transportation. Contrary to Ethiopia, ascending the mountain in Israel is not on foot but with vehicles. This expresses an essential change in the essence of the pilgrimage as a means for a person's self-denial for the forgiveness of his sins.

The adults arrived fasting and wearing traditional white clothes. Some placed small stones under the stage, where the ritual was held. With this symbolic act, they wanted to preserve, with 
some change, an ancient custom of carrying a stone up to the mountain top, which symbolized submission (Abbink, 1983). Many youth arrived, school pupils, soldiers, members of youth movements, and students. A small part fasted. Most did not dress appropriately for a religious event. The kessoch arrived from nine in the morning, wearing white caps and magnificent embroidered robes. Each kess was accompanied by a person who carried a splendid parasol that indicted his high status, as well as a person carrying the Torah scroll.

At ten o'clock, the kessoch mounted the stage and began praying in the Ge'ez language, and one of the kessoch translated the prayers into Amharic, which the audience understood. Prayers included praises to God for redeeming them from exile, asking for forgiveness, and expressing a yearning for the rebuilding of the Temple. The praying audience, especially the adults, crowded around the kessoch, the men in front and the women behind. Religious youth prayed together with the adults. However, many youths remained far from the stage and arrived for a social encounter (Pikado, 2007; Maharat, 2001).

From twelve until one o'clock, there was a break for speeches by public figures who wanted to appear before a large potential electorate. They complimented the Ethiopian immigrants on their unique culture, stressed their actions for this community, and promised support in turning the Sigd into a national holiday (Adamaso, 2005; Adino, 2007).

In an interview, Mula Kasai referred to the deviation from the ritual tradition by inviting politicians (Sivan \& Fredo, 2002). He said that to achieve the goal of exposing the holiday to the general public, it was necessary to recruit the media, which will come only if public figures are present, who will give political speeches. He further indicated that leaders of the community try to avoid having the Sigd turn into "a day of political parties", similarly to the Mimouna holiday of the immigrants from North Africa. However, the politicians exploit the stage during the Sigd, in spite of requests of the leaders of the Ethiopian community.

Nonetheless, it became clear the Mula himself exploited the mass gathering of the Sigd in order to raise problems of the community to the public agenda, and to communicate political messages. Mula and his friends, the 1.5 generation leaders, who deposed the kessoch from their traditional role of setting the schedule for the Sigd, used the politicians and the media. They added this secular ritual element with the goal of disseminating the holiday and legitimizing it, through adoption of components of Israeli society.

After the speeches, from one until two o'clock, the kessoch continued with prayers. The senior kess preached to the praying audience on the importance of fulfilling the laws of the Torah and about community solidarity, with a wish that they would celebrate next year. At two o'clock, the ritual ended. Because it was impossible to hold a collective meal for so many people, the tradition of the community meal was not preserved as in the past. As a symbolic act for this meal, the kessoch made a blessing over traditional bread (dabu) and divided it among the people around them.

\section{A Bridging Holiday}

The interviews and the written sources indicate that in the first decade of the $21^{\text {st }}$ century, many of the older kessoch who viewed the Sigd as a holy day of prayer, purification and fasting, still adamantly objected to changes in the holiday (Masala, 2002). In contradistinction, socialpolitical leaders of the 1.5 generation, headed by Mula Kasai, were the dominant stream that led to changes in the Sigd and the community's tradition.

These young leaders wanted to renew the holiday's contents and adapt it to the younger generation of Ethiopians and Israeli society. Their motive was ethno-political. They regarded the 
Sigd as a means for unity and for advancing their community, for a demonstration of ethnic identity, for exposure of their tradition to the Israeli public, and for achieving recognition. Against the background of the objection of the kessoch, they wanted to be a bridging factor between the youth and the adults.

Mula indicated that his organization tried to find ways to mobilize the youth of the community and to enable them to participate in the celebration without harming the kessoch. $\mathrm{He}$ said: "We must strive to present the Sigd as a holiday that bridges and connects between the leadership of the kessoch and tradition, and the younger generation and the society in which we live" (Adamaso, 2002).

In another interview, Mula indicated that the change in the holiday stems from the move to Israel. In his opinion, it is impossible to transcribe the holiday precisely as it was celebrated in Ethiopia, and it must be adapted to the new framework in order to preserve the culture. He also said that every year, after the ceremony, many of the youth come to him with requests to change the ritual: "The youth would like to see new content and to give the holiday meaning. Youth who were educated in Israel have difficulties in becoming integrated in the holiday and are interested in adapting it to Israeli society" (Sivan \& Fredo, 2002).

The adaptation to which Mula referred is not only a strategy for intergenerational connection. It has implications for the status of the kessoch in the ritual because it means that the youth are becoming more active and involved, contrary to Ethiopia, where control was in the hands of the old kessoch. Against the background of their exclusion in Israel, Mula is aware of the sensitivity to their status in the community and to their fear of losing the source of authority that was left them in the Sigd. Identification of the social activists of the community, headed by Mula Kasai, with the kessoch, curbed drastic changes in the ritual system of the Sigd in this decade, and moderate syncretism was created.

\section{To Adapt to the New Circumstances}

The Steering Center for Ethiopian Immigrants in the Education System (2004) was established in 1994 to advance the absorption of Ethiopian pupils. The head of the center, Aaron Makonan, emigrated in the 1980s, at age 18, and therefore fits the definition of 1.5 generation. Aaron declared:

We strive to draw the youth to the spiritual and Jewish meaning of the Sigd holiday and to connect members of the community to the culture from which they came. The Sigd has meanings with which every Jew can identify. If we succeed in adapting the Sigd to the new circumstances of life in Israel, we hope it will receive recognition as a holiday of all Jews of Israel and around the world (Maharat, 2007a).

The Steering Center operated its program via Ethiopian educational mediators employed in educational institutions that include groups of Ethiopian pupils. Each mediator prepared special activities on the Sigd as well as the culture and immigration of the Ethiopian Jews, in his or her educational institution. These activities were intended for all pupils, with the cooperation of the educational team, the pupils, the parents, and the community's kessoch (Carlebach \& Shapira, 2001; Maharat, 2006). The Sigd celebration afforded the Ethiopian pupils a sense of ethnic pride and communicated the message that it is a holiday of the entire institution, which adopts it as part of the Jewish calendar. 
The Steering Center for Ethiopian Immigrants in the Education System initiated a conference in a high school in Jerusalem for the first time on the eve of the Sigd in 2006, which became a tradition. The conference, which was organized with the collaboration of the Ministry of Education and the Ministry of Absorption as well as the community's organizations, was intended to draw the youth to the significance of the Sigd. Aaron Makonan presented his doctrine regarding the inclusion of the Sigd in society at the conference:

The Sigd can be turned into a universal Jewish holiday. One day a year, the Jews express their yearning for Jerusalem in prayer. A day of connecting to our Jewish origins. The holiday can symbolize the strengthening of our belonging to the land. This can be a social holiday, where the community of immigrants from Ethiopia exhibits its spiritual treasures to Israeli society. We can also think of innovations that should be introduced in order to fill it with contents according to the circumstances of the time and place (Maharat, 2006).

Aaron's sayings indicate that these social-political leaders regarded the Sigd as a means for bridging between generations in the community and also between the culture of the Ethiopian Jews and Israeli culture. They wanted to perform adaptations in its contents to the new reality and create syncretism between tradition and modernity, which also preserves the dignity of the kessoch. The young leaders stressed that the Sigd was relevant not only for the Ethiopian Jews but also for society. The practical significance is the recognition of the Sigd as a link integrated into the collective Israeli identity. In this demand, they put Israeli multiculturalism to the test.

\section{Celebrating in the Youth Movements}

Organizations of the immigrants from Ethiopia also "recruited" youth of the community movements for advancing the Sigd among the young of the community because they viewed them as important agents of socialization for connecting the youth to the community and communicating the messages of the holiday to the society. The youth movements cooperated out of identification with the spiritual and social messages of the Sigd and out of a desire to advance multicultural openness among their members (Maharat, 2004, 2007b).

The Bnei Akiva movement, as a religious-national movement that identified with the socialreligious messages of the holiday, was prominently active in the celebrations. After preparations for the Sigd, hundreds of adult Bnei Akiva alumni, instructors, and coordinators arrived for the celebration in Jerusalem via organized transportation. They sang and danced to the sounds of Amharic music, handed out information pamphlets, and gave explanations about the holiday in a tent they set up (Maharat, 2007b).

The Scouts movement was also included in the celebrations. It founded a division for Ethiopians called Inclusion of Ethiopian Jews (Sheba) to draw them toward the movement and its values and encourage a multicultural perspective among its members. Hundreds of instructors and members, about half of them Ethiopians, arrived at the celebrations. In a tent they set up, they handed out information pamphlets and organized holiday activities (Hadas, 2005; Pikado et al., 2005).

Jacob Negat, head of the Sheba movement, emigrated from Ethiopia in 1984, at the age of about ten, and therefore meets the definition of 1.5 generation. He served as the CEO of the Israel 
Association of Ethiopian Jews from 2009 (News - Opinions, 2010). Jacob attributed a broad meaning to the Sigd and viewed it as a bridge to Israeli society. In his opinion:

The Sigd represents the community's culture and customs. Through it we can communicate our values to the youth and to the general Israeli public. The holiday affords an opportunity to influence Israeli society.... This is an opportunity to strengthen the community's pride in our unique identity and the connection of the youth to the past and to their parents. Communication of messages to youth and children must be performed using appropriate educational methods. We must act for recognition of our cultural difference and regard it as an asset, as part of the cultural puzzle of Israeli society. One of the suitable ways is the youth movement, where youth of the community meet the culture, custom and youth from all parts of Israeli society (Pikado et al., 2005).

Jacob's sayings indicate that the activists among the young Ethiopian immigrants, members of the 1.5 generation, regarded the youth movements and schools as a means for recognizing the community's culture. He speaks assertively, where the mutual message was: through the activity on the Sigd holiday, you will not only become acquainted with me, I will influence you, and my cultural values will become an integral part of the collective Israeli identity.

\section{National Recognition}

Jacob Negat, CEO of the Israel Association of Ethiopian Jews, led the struggle for government recognition of the Sigd holiday. On 5 November 2007, he wrote a letter to the Chief Rabbis of Israel and stressed:

Fortunately, the Judaism of the Ethiopian Jews brought us a holiday that is thousands of years old, the Sigd holiday that was celebrated every year on November 29. The Israel Association requests, in the name of all Ethiopian Jews, to accept the Sigd holiday as a formal holiday of the Jewish People (Nagat, 2007).

Jacob's request to recognize the Sigd as an official Jewish holiday is brief but well-argued. On the background of the doubt that was cast on the Judaism of the immigrants from Ethiopia, he, as well as his fellow leaders, again and again, repeat the argument that is motivated from a position of power, from the religious advantage of the Ethiopian Jews over other Jewish communities. The message was, not only are we Jews, we now contribute an ancient holiday to the Jewish People that only we preserved and maintained.

In the 2007 Sigd celebration, the Israel Association of Ethiopian Jews had the celebrators sign a petition calling on the Chief Rabbis to make a bold but inevitable decision to include the Sigd as one of the Jewish holidays (Maspin, 2008). Young kessoch also supported this struggle, and it merged with the struggle over their status in Israel. The combined struggle was successful, and in June 2008, the Israeli parliament approved the Sigd Law that states that it will be celebrated every year on November 29, as a national holiday, with a status similar to other holidays.

The social-political leaders of the community, members of the 1.5 generation, expressed their satisfaction and indicated that they regard the recognition of the Sigd as a lever for the 
empowerment of the community. They also expressed the expectation that the Sigd would now join Israeli society, similar to the Mimouna of the immigrants from North Africa, which served as their model. However, they asked to emphasize their cultural uniqueness, and in the name of their call for unity, expressed hope for real equality and inclusion of their community in Israeli society. Jacob Negat stressed the significance of this achievement:

This law is more than just a symbol. It is a positive penetration of the Ethiopian Jews' culture into the Israeli hegemony and mainstream. This is an important step in future assimilation of important values of the Ethiopian community in Israeli society (Feldman, 2007).

A few years later, in his greetings in one of the Sigd events, Jacob added:

This holiday empowers. The fact that the tradition which was preserved for 2500 years still exists, is a source of pride for the entire community. For the youth, this holiday returns them to their roots, to delving into the magnificent history of the community. It instills the youth with great motivation to come and celebrate. We are happy that the Sigd Law has turned it from an Ethiopian holiday into a national holiday. Nonetheless, in spite of the desire to enter Israeli society, there are still significant gaps in the fields of education, employment and others. I hope that all of us, as a Jewish People with values of unity, will lead to the expression of our values and that we will all become included (Karash-Hazony, 20.11.2009).

Aaron Makonan, head of the Steering Center for Ethiopian Immigrants in the Education System, said:

I am glad that the Sigd received the status of a national holiday in the State of Israel. This move strengthens our feeling that we contribute our cultural assets to Israeli society. In a country that absorbs immigrants, such as Israel, there is great significance to the fact that every immigrant can bring something from his culture, and in this way, we can create a diverse society. An immigrant who feels that he also contributes and not only receives will be much more open to accepting other cultures. He will feel greater belonging. The Ethiopian Jews preserved the Sigd holiday in the diaspora... Today we hand its preservation to the entire Jewish People. I hope that in the future the entire people will be exposed to the traditions that were preserved by the community in Ethiopia (Maharat, 2008).

Aaron does not sound apologetic as the representative of a minority group trying to become included in Israeli society, but rather indicates ethnic pride. He and his friends demanded a mutual process of absorption between absorbed and absorbers, for syncretism between the culture of the Ethiopian immigrants and Israeli society. Aaron wanted to communicate a covert and overt message: We, the immigrants from Ethiopia, must be citizens with equal rights by right and not by sufferance. We are actually the original Jews. Come learn from us.

In the years after the Sigd was given national recognition, the community's organizations made numerous attempts to afford the holiday a broader national character. This is apparent in the 
broad distribution of the holiday events in the geographical space, in Jerusalem and outside, and in the time dimension (Karash-Hazony, 2009; Events of the Sigd Holiday, 2010; Klein, 2016).

For weeks before and after the religious ritual, events were held with government and municipal funding: movies, plays, culture evenings, study evenings for youth on the significance of the Sigd, musical events, and a festival of Ethiopian-Israeli art, among others. The organizers made an effort to disseminate and assimilate the holiday with an emphasis on culture, which is a broad denominator that may draw the youth of the community and the Israeli public. The peak event was the religious ritual on the Sigd day in Jerusalem, where a fixed ritual element was preserved: the centrality of the kessoch in conducting the prayers.

\section{Discussion and Conclusions}

This article discusses the ethnic activism of social-political leaders, members of the 1.5 generation (who immigrated when they were older than eight years), in advancing the ethnicreligious holiday called the Sigd, and the tradition of the Ethiopian Jews in the cultural mainstream in Israel. The Sigd is a pilgrimage holiday that is unique to the Ethiopian Jews, which was celebrated on the $29^{\text {th }}$ of November. This is a day of fasting, purification, and prayer which takes place in high places, during which the religious priests read portions of the Torah and held prayers for redemption in the Land of Israel.

On a background of their cultural differences, skin color, and the doubt that was cast on their Judaism, immigrants from Ethiopia cope with discrimination, social alienation, and harm to the status of their older religious leaders (the kessoch). The central place of the kessoch in the Sigd and in leading the community was taken over by educated youth, members of the 1.5 generation, who headed Ethiopian immigrants' organizations. This article attempted to explore: how the Sigd, which is not an entertaining holiday, and which represented an ethnic group whose Judaism was doubted, became institutionalized thy these Ethiopian leaders, members of the 1.5 generation, in Israel; what are the relevant meanings which they afforded the holiday, and how did they preserve traditional ethnic characteristics within the new social context.

While the theoretical model of the 1.5 generation posits two poles of behavior patterns: assimilation or resistance, the findings of this article presents a bipolar identity of simultaneous integration and protest. I claim that actually, syncretism, which means a mixing of different traditions, was created in the identity and behavior patterns of social-political leaders, members of the 1.5 generation of the Ethiopian community. This cultural pattern is considered to be a form of resistance to different types of control and as a strategy for cultural negotiation (Mayaram, 2012; Zhang et al., 2018). This syncretism was expressed in the organization of the Sigd celebrations. I claim that the syncretism that was created in the Sigd celebrations in Israel and its mobility toward the cultural center was from the onset initiated by the leaders of the immigrants from Ethiopia, members of the 1.5 generation. They aspired to create a renewed, syncretic Sigs by means of a selective return to their roots, which would advance their goal of connecting the holiday to new audiences within and without their community.

Continuity of the traditional characteristics was expressed in the religious ritual on a mountain, the kessoch as a central religious symbol, a (shortened) prayer by the kessoch in the ancient Ge'ez language, celebrators dressed in white clothes, fasting (mainly the adults) and more; a social encounter and a strengthening of their unique identity. The changes in the traditional nature were expressed in holding one central ritual; arriving by vehicles, which abolish the essence of the Sigd as a holiday of pilgrimage; cessation of the custom of carrying stones up the mountain; activities of organizations and youth movements at the celebration site; participation of celebrators 
who are not members of the community; speeches of politicians during the ritual; absence of a collective meal.

In addition to the religious ritual in Jerusalem, the 1.5 generation leaders initiated Sigd celebrations that did not exist originally. These were spread over the geographical space and over time (in the weeks before and after the religious ritual), and were intended for the general Israeli public. For example, an opening event at the Israeli President's house, activities in schools, seminar evenings, a festival, and more. These were modern festivities, where the young leaders of the community stressed the common denominator of ethnic culture, which included: arts, music, food and dances of the Ethiopian Jews. Thus we witness the growth of a renewed syncretic Sigd that reflected the goals of the organizers, to connect the young generation to the community and tradition; to advance issues of the community; to connect the Israeli public to the community's culture; and to obtain national recognition for the holiday.

A central dimension of leadership behavior is to take social responsibility for a collective. A leaders of this type does not view this as a mean for earning a living, even if he does make money from it. This leadership involves a willingness to make sacrifices on the personal level in order to solve a problem on the social level, out of a sense of identification and empathy that the leader feels about a particular issue. This initiative is attributed to the leader in a situation where he or she identifies the possibility of a change in the existing circumstances (Oliver-Lumerman et al., 2018). It seems that this is also how the leaders of the Ethiopian community acted. These are social activists who suffer the pain of the community's exclusion, demand equal rights, and use the Sigd to advance their social-political agenda as educated Israelis, speakers of the Hebrew language who are familiar with Israeli culture. Contrary to the conformity of the youth in Ethiopia, and the passivity that characterized the adult kessoch (Kaplan \& Sharaby, 2018), they adopted a demanding Israeli style.

The young leadership took it upon itself to create "syncretism from the bottom" in the immigrants" tradition and "syncretism from the top" in the absorbing society's culture. Due to the ethnic activism they expressed, they can be referred to as "initiators of identity" (Eisenstadt, 2013, p. 427), since not only did they protest against the discrimination of their ethnic group, they acted to introduce its cultural symbols into the public sphere. They fight for the right to ethnic otherness and their desire to become included in the Israeli space as such. In their declarations, they discussed the importance of ethnic celebrations as a factor that unifies the people and stressed the symmetry of this unity, where they are part of the people. Such calls are not an expression of cultural segregation, but rather an attempt to expand the boundaries of Israeli culture and include repertoires that did not exist in it previously (Sharaby, 2009).

Transferring ethnic celebrations to Israel is not a new phenomenon. The anthropological literature has discussed ethnic spring celebrations: the Mimouna of the Jews of North Africa (Goldberg, 1984; Sharaby, 2009), and the Seharane, which originates in Kurdistan (Halper \& Abramowitz, 1983; Sharaby, 2017). An essential element in these events is the demonstration of the ethnic identity of the minority group to receive recognition for their ethnic holiday and their cultural tradition from the majority in the country. Important means for achieving this goal were: inclusion of elements of tradition and modernity in the celebrations; participation of other populations; and speeches by public figures. These ritual elements also played a major role in the transfer of the Sigd to Israel.

The cultural celebrations and traditions of these and other ethnic groups, such as from Iran and Georgia (Sharaby, 2019; 2020c) did indeed serve as an imitation model for the Ethiopian leaders, but with a significant difference. Immigrants from Morocco, Kurdistan, and other places wanted their point of origin for defining their position as Israelis to be via their tradition, which 
was perceived as part of Jewish culture. In contradistinction, advancing the ethnic holiday of the Ethiopian immigrants involved unique difficulties for several reasons (see also Abbink, 1983). They coped with the issue of the confirmation of their identity as Jews; the Sigd as a day of prayer and fasting was not entertaining or attractive, as were other ethnic celebrations; because their aspiration to immigrate to Israel was realized, the leaders of the Ethiopian immigrants had to solve to problem of the relevance of the Sigd and impart it with a new interpretation.

The young Ethiopian leaders expressed their strong desire to include the Sigd and the Ethiopian Jews in the Jewish People. In a defiant vein, they stressed the original contribution of the Ethiopian Jews: we have an ancient custom which we preserved and was forgotten in other Jewish communities around the world. Now, we are willing to return it to the entire Jewish People. Against a background of the doubting of their Judaism, this saying presented them as "better Jews" who preserved the original tradition of the Jewish People. It also positions them, as an absorbed minority group, in a better position of power.

Emphasizing the idea of the relevance of pan-Jewish and pan-Israeli aspects of the holiday in their declarations stressed the role of these leaders, members of the intermediate generation in the community, as a bridge between generations, between the absorbing and the absorbed, between past and present, between tradition and modernity and between national and ethnic identity.

\section{Policy Implications}

The twenty-first century is home to diverse ethnic groups, religions, and cultures in Europe and the United States. A large part of these originate in immigration of ethnic groups who cross borders, including refugees and migrant workers (Alba \& Nee, 2003; Geddes \& Scholten, 2016; Strunc, 2020). However, hostility and fear of the immigrants exists alongside this human and cultural diversity, which pose significant challenges to traditional perceptions of nationalism, ethnicity and citizenship (Barrett et al., 2011; Tarman \& Gürel, 2017). The present article supports voices in the literature that call on multicultural nations that are interested in "including" their new immigrants, to reexamine their policies, in particular policies regarding those who immigrated from non-democratic countries. They must demand a certain degree of identification with the values of the majority, but beyond that should enable the immigrants to preserve their ethnic identity according to their choice (Modood, 2012). This, in order to give them a feeling of "home" in the new society.

The construct "home" has multiple meanings (Chaitin et al., 2009). For immigrants, the meaning of home is usually a concept that holds tension and different meanings for different generations, with reference to the country in which they live or the place they came from (Duncan $\&$ Lambert, 2004). The question of where do I belong, pertains to many people, due to the multiple spaces and identities to which they may belong over the course of their lives (Eisenberg, 2019; Yuval-Davis et al., 2005).

The present study may contribute to the attempt to understand leadership patterns of immigrants, members of the 1.5 generation, and supply important insights into the manner in which young leaders of immigrants use ethnic traditions as a resource for recruiting cultural, social and political capital for uniting the minority group and including it in society. It further suggests considering mechanisms of containment for the culture of ethnic minorities in multicultural societies via dialogue with their leaders. 
Sharaby, R.

\section{Acknowledgements}

This research was supported by the Research Committee of Ashkelon Academic College, Israel.

\section{References}

Abbink, J. (1983). Seged celebration in Ethiopia and Israel: Continuity and change of a Falash religious holiday. Anthrops, 78, 789-810.

Adamaso, D. (2005). Revavot ba'Sigd [Tens of thousands at the Sigd]. Pana Lapid - Journal of the Israel Association of Ethiopian Jews, 27, 6 (Hebrew).

Adino, D. (2007, November 9). Hogegim ve'hoshvim [Celebrating and thinking]. Yedioth Aharonoth, p. 8 (Hebrew).

Alba, R., \& Nee, V. (2003). Remaking the American mainstream. Harvard University Press.

Alba, R., \& Waters, M. (2011). The next generation: Immigrant youth in a comparative perspective. New York University Press.

Anoegrajekti, N., Sariono, A., Macaryus, S., \& Kusumah, M. S. (2018). Banyuwangi ethno carnival as visualization of tradition. Cogent Arts \& Humanities, 5(1), 1-16.

Anteby-Yemini, L. (2002). Ethiopia ha'urbanit ve'tarbut shechora: Modelim shel zehut hadasha bekerv noar oleh me'Ethiopia be'Israel [Urban Ethiopia and black culture: New identity models among Ethiopian youth in Israel]. In R. Eisikovits (Ed.), Al gevulot tarbutiyim ve'beneihem [On cultural borders and in between] (pp. 11-31). Ramot (Hebrew).

Bar-Yuda, M. (1990). Hag ha'Sigd etzel yehudai Ethiopia [The Sigd holiday among the Ethiopian Jews]. In R. Sharet (Ed.), Ha'hag h'adati be 'Israel [The ethnic holiday in Israel] (pp. 2122). Ha'histadrut Ha'clalit (Hebrew).

Barbera, M. (2015). Identity and migration in Europe. Springer.

Barrett, M., Flood, C., \& Eade, J. (Eds.) (2011). Nationalism, ethnicity, citizenship. Cambridge Scholars.

Bass, B. M. (2009). The Bass handbook of leadership. Free Press.

Ben Rafael, E., \& Peres, Y. (2000). Identity nationalism and multiculturalism. In E. Ben Rafael \& Y. Peres (Eds.), Is Israel one? Religion nationalism and multiculturalism confounded (pp. 3-26). Brill.

Ben Simon, B., Levi, D., \& Kahan-Strawczynski, P. (2019). Hagorem ha'enoshi: Tefisat studentim yotzei Ethiopia et hagormim hamesayim le'hatzlacha ba'akademia [The human factor: Ethiopian students' perception of the factors that help in success in the academia]. Hagira, 9, 111-136 (Hebrew).

Ben-Dor, S. (1985). Ha'Sigd shel Beta Israel [The Sigd of Beta Israel]. MA thesis, The Hebrew University (Hebrew).

Ben-Ezer, G. (2010). Ketipa hashava el ha'yam? Nirut ve'i nirut be'tahalich ha'klita shel Yehudei Ethiopia [As a drop that returns to the sea? Visibility and invisibility in the process of absorption of the immigrants from Ethiopia]. In E. Lomsky-Feder, T. Rapoport \& L. Ginsberg (Eds.), Nirut be'hagira [Visibility in immigration] (pp. 328-305). Van Leer (Hebrew).

Bronner, Y., \& Shulman, D. (2020). Ayin le'Hodu [An eye to India]. Magnes (Hebrew).

Carlebach, V., \& Shapira, S. (2001). Ha'Sigd [The Sigd]. Ha'merkaziya Ha'chinuchit (Hebrew).

Central Bureau of Statistics. (2019). Hodaa la'tikshoret al ha'ochlosiya mimotza Ethiopi be'Israel: Leket netunim leregel hag ha'Sigd [Announcement to the press on the Ethiopian population in Israel: A collection of data in honor of the Sigd holiday]. http://www.cbs.gov.il>mediarelease>pages>2019 (Hebrew). 
Cesana, S. (1995, November 23). Hag ve'heshbon nefesh [Holiday and self-scrutiny]. Ma'ariv, p. 23 (Hebrew).

Chaitin, J., Linstroth, J. P., \& Hiller, P. T. (2009). Ethnicity and belonging: An overview of a study of Cuban, Haitian and Guatemalan immigrants to Florida. Forum: Qualitative Social Research, 10(3), 1-25.

Collard, J. (2007). Constructing theory for leadership in intercultural contexts. Journal of Educational Administration, 45(6), 740-755. https://doi.org/10.1108/09578230710829919

Corinaldi, M. (2005). Yahadut Ethiopia [Ethiopian Jewry] Rubin Mass (Hebrew).

Costigan, C., Tina, S., \& Josephine, H. (2009). Ethnic identity among Chinese Canadian youth: A review of the Canadian literature. Canadian Psychology, 50(4), 261-272.

Croucher, C., \& Kramer, E. (2017). Cultural fusion theory. Journal of International \& Intercultural Communication, 10(2), 97-114.

Della Pergola, S. (2016). Machshavot al medinat liba ve'hizdahut Yehudit [Thoughts about a core state and Jewish identification]. Hagira, 5, 159-186 (Hebrew).

Duncan, J., \& Lambert, D. (2004). Landscapes of home. In J. Duncan, J. Nuala, \& R. Schein, R. (Eds.), A companion to cultural geography (pp. 382-403). Blackwell.

Eisenberg, S. (2019). Havnayat shayachut kegorem hayotzer motivatziya lelimud safa zara [Construction of belonging as a factor that creates motivation to learn a foreign language]. In G. Sabar \& S. Efrat (Eds.), Mevakshei haim [Searchers of life] (pp. 191-210). Pardes (Hebrew).

Eisenstadt, S. N. (2013). Aharit davar [Epilogue]. In Z. Shavit, O. Sasson-Levy, \& G. Ben-Porat (Eds.), Marei makom [Points of reference] (pp. 416-429). Hakibbutz Hameuchad (Hebrew).

Elia-Leib, R., Harel-Shalev, A., \& Tekoa-Shir, D. (2018). Mi'kehila muchleshet le'kehila ne'eveket [From a weakened community to a fighting community]. Hevra Ve'revacha, 38(4), 801-829 (Hebrew).

Engdaw-Vanda, S. (2019). Chosen be'hagira [Strength in immigration]. Resling (Hebrew).

Events of the Sigd Holiday. (2010). cms.education.gov.il/NR/rdonlyres/2F7451EF-623F-4C8E90E4.../alon.pdf

Feldman, Y. (2007, July 2). Hag hadash le'Israel [A new holiday for Israel]. Kipa (Hebrew). https://www.kipa.col.il> יהדות

Geddes, A., \& Scholten, P. (2016). The politics of migration and immigration in Europe. Sage.

Goldberg, H. (1984). Hagigot ha'Mimouna be'Morocco [The Mimouna celebrations in Morocco]. In S. Deshen \& M. Shokeid (Eds.), Yehudei ha'mizrach [Jews of the East] (pp. 106-116). Schocken (Hebrew).

Hadas, A. (2005). Zofei SHABA be'beit ha'nasi [Scouts who integrate Ethiopians at the President's home]. Pana Lapid - Journal of the Israel Association of Ethiopian Jews, 27, 7 (Hebrew).

Halper, J., \& Abramowitz, H. (1983). Hagigot ha'Seharane be'Kurdistan ve be'Israel [The Seharane celebrations in Kurdistan and in Israel]. In S. Deshen \& M. Shokeid (Eds.), Yehudie ha'mizrach [Jews of the East] (pp. 260-270). Schocken (Hebrew).

Hodzi, O. (2019). Chinese in Africa: 'Chineseness' and the complexities of identities. Journal of Asian Ethnicity, 20(1), 1-7.

Hofstede, G., \& Hofstede, J. (2010). Culture and organizations. McGraw-Hill.

Honegger, M. (2020). What Does "Education" Mean: Cultural Values in Educational Language. Journal of Culture and Values in Education,3(2), 42-53. https://doi.org/10.46303/jcve.2020.12

Josephsberg Ben-Yehoshua, L. (2013, November 1). Brit berosh ha'har [Covenant on the mountaintop]. Maariv, pp. 4-5 (Hebrew). 
Kaplan, A., \& Sharaby, R. (2018). Variations of identities among the leaders of a minority group of immigrants". Social Identities -Journal for the Study of Race, Nation and Culture, 3, 403-411.

Karash-Hazony, H. (2009, November 20). Hag ha'kisufim le'Zion [Holiday of yearning for Zion]. Makor Rishon, pp. 20-21 (Hebrew).

Keefer, N., \& Haj-Broussard, M. (2020). Language in Educational Contexts. Journal of Culture and Values in Education, 3(2), 1-12. https://doi.org/10.46303/jcve.2020.9

Kibria, N. (2000). Race, ethnic options and ethnic binds: Identity negotiations of second generation Chinese and Korean Americans. Sociological Perspectives, 43(1), 77- 95.

Kim, R. (2011). Religion and ethnicity: Theoretical connections. Religions, 2, 312-329.

Kipper, D. (1989, November 28). Tefila leshlom Yehudei Ethiopia [Prayer for the wellbeing of the Ethiopian Jews]. Yedioth Aharonoth, p. 9 (Hebrew).

Klein, Z. (2016, November 30). Hitgashmut halom [Realization of a dream]. NRG News in Israel (Hebrew).

Koepping, K. P. (1994). Manipulated identities: Syncretism and uniqueness of tradition in modern Japanese discourse. In C. Stewart \& R. Shaw (Eds.), Syncretism /Anti Syncretism. Routledge.

Lehman, C., \& Welch, B. (2020). A Quantitative Investigation of Language Policy in International Schools in East Asia. Research in Educational Policy and Management, 2(2), 1-18. https://doi.org/10.46303/repam.2020.1

Leopold, A. M., \& Jensen, J. S. (2004). General introduction. In A. M. Leopold \& J. S. Jensen (Eds.), Syncretism in religion (pp. 2-12). Routledge.

Lev-Ari, L. (2010). Dor sheni ve'dor vachezi shel Yisraelim be'zforn America [Second generation and one and a half generation of Israelis in North America]. Publication no. 20, Bar-Ilan University, Rapoport Center (Hebrew).

Lev-Ari, L. (2012). Haim migdar nashpiya bedor sheni le'hagira? Zehut ve'hizdahut etnit bekerv tzeizaei mehagrim Yisarelim [Does gender influence the second generation immigrants? Ethnic identity and identification among children of immigrants in Israel] Sugiot Hevratiot Be'Israel, 14, 208-236 (Hebrew).

Levitt, P., \& Glick-Schiller, N. (2004). Conceptualizing simultaneity: A transnational social field perspective on society. International Migration Review, 38(3), 1002-1039. https://doi.org/10.1111/j.1747-7379.2004.tb00227.x

Liebkind, K. (2006). Ethnic identity in acculturation: A social psychological perspective. In D. L. Sam \& J. W. Berry (Eds.), The Cambridge handbook of acculturation (pp. 87-96). Cambridge University Press.

Maccoby, M. (2009). Hamanhigim she'anu zerichim [The leaders we need]. Matar (Hebrew).

Maharat, D. (1999). Beshana haba'a be'Yerushalayim [Next Year in Jerusalem]. Yedioth Negat, 1, 2 (Hebrew).

Maharat, D. (2001). Lisgor et ma'agal hakapara [To Close the Atonement Circle]. Yedioth Negat, 11, 9 (Hebrew).

Maharat, D. (2004). Mabat al ha'Sigd [A Look at the Sigd]. Kav Ha'Ofek, Journal of the Israel Association of Ethiopian Jews, 19, 10-11 (Hebrew).

Maharat, D. (2006). Lechadesh et ha'hag [To Renew the Holiday]. Yedioth Negat, 38, 6-7 (Hebrew).

Maharat, D. (2007a). Sigd la'kol [Sigd for Everyone]. Yedioth Negat, 39, 6 (Hebrew).

Maharat, D. (2007b). Hag ha'Sigd betnuat Benei Akiva - Hizdamnut lehitchaber [The Sigd in the Bnei Akiva Movement - A Chance to Connect]. Yedioth Negat, 44, 1-7 (Hebrew). 
Maharat, D. (2008). Ha'Sigd hag leumi be'Israel [The Sigd is a national holiday in Israel]. Yedioth Negat, 50, 1 (Hebrew).

Masala, A. (2002). Ha'Sigd be Israel [The Sigd in Israel]. Israel Association of Ethiopian Jews (Hebrew).

Maspin, A. (2008). Hoda'a la'tikshoret: Kehilat olei Ethiopia [Press release: The Ethiopian community]. Site of the Israel Association of Ethiopian Jews. Retrieved December 2020, from iaej.co.il (Hebrew)

Mayaram, S. (2012). Syncretism. In M. Juergensmeyer \& W. Clark-Roof (Eds.), Encyclopedia of global religion (Vol. 2, pp. 1250-1252). Sage. http://site.ebrary.com/id/10581839

McCorkle, W. (2020). Problematizing Immigration Restrictions during COVID-19 in the Social Studies Classroom. Research in Social Sciences and Technology, 5(3), 1-24. https://doi.org/10.46303/ressat.05.03.1

Min, P., \& Kim, R. (2000). Formation of ethnic and racial identities: Narratives by youth AsianAmerican professionals. Ethnic \& Racial Studies, 23(4), 735-760. https://doi.org/10.1080/01419870050033702

Modood, T. (2012). Post-immigration 'difference' and integration: The case of Muslims in Western Europe. The British Academy.

Morales, J., \& Bardo, N. (2020). Narratives of Racial Reckoning: Oppression, Resistance, and Inspiration in English Classrooms. Journal of Culture and Values in Education, 3(2), 138157. https://doi.org/10.46303/jcve.2020.17

Nagat, Y. (2007, November 8). Lichlol et chag ha'Sigd [To Include the Sigd Holiday]. MakorRishon/Hazofe, p. 6 (Hebrew).

News - Opinions. (2010, March 30). Makor Rishon (Hebrew). https://makorrishon.co.il >nrg>online>ART2

Oliver-Lumerman, A., Zilber, T., \& de Shalit, A. (2018). Manhigim chevartiyim be'Israel [Social leaders in Israel]. Magnes (Hebrew).

Paganoni, A. (2003). Valiant struggles and benign neglect. Center for Migration Studies.

Park, J. Z. (2008). Second-generation Asian American pan-ethnic identity: Pluralized meanings of a racial label. Sociological Perspectives, 51(3), 541-561. https://doi.org/10.1525/sop.2008.51.3.541

Pikado, B. (2007). Kol Israel hogegim [All of Israel is celebrating]. Yedioth Negat, 44, 6 (Hebrew).

Pikado, B., Geta, M., Fredo, M., \& Lijishal, I. (2005). Yom kadosh o' happening hevrati [A holy day or a social happening]. Yedioth Negat, 31, 6-7 (Hebrew).

Popper, M. (2002). Narcissism and attachment patterns of personalized and socialized charismatic leaders. Journal of Social and Personal Relations, 17(6), 796-808. https://doi.org/10.1177/0265407502196004

Popper, M. (2007). Manhigut me'atzevet [Transformative leadership]. Tel-Aviv University (Hebrew).

Popper, M., \& Maysless, O. (2003). Back to basics: Applying parenting perspective to transformational leadership. Leadership Quarterly, 14(1), 41-65. https://doi.org/10.1016/S1048-9843(02)00183-2

Portes, A., \& Rumbaut, R. G. (2001). Legacies. University of California Press.

Prashizky, A., \& Remennick, L. (2017). Dovrei Russit be'Israel: Nitzaneha shel mecha'a etnic [Young Russian speakers in Israel: The first signs of a ethnic protest]. Iyunim Bitkumat Israel, 27, 7-49 (Hebrew). 
Sharaby, R.

Prashizky, A., \& Remennick, L. (2018). Celebrating memory and belonging: Young Russian Israelis claim their unique place in Tel-Aviv's urban space. Journal of Contemporary Ethnography, 47(3), 336-366.

Purkayastha, B. (2005). Negotiating ethnicity. Rutgers University Press.

Ramsey, C., \& Ricket, A. (2020). Examining Physical Space, Leadership Inheritance, and "Authentic" Community Engagement through Co-Constructed Autoethnography. American Journal of Qualitative Research, 4(3), 161-178. https://doi.org/10.29333/ajqr/9338

Reichman, R. (2009). Hagira le'Israel: Mippui megamot ve'mechkarim empiriim 1990-2006 [Immigration to Israel: Mapping trends and empirical studies 1990-2006]. Sociologia Yisraelit, 10(2), 339-379 (Hebrew).

Remennick, L. (2003). The 1.5 generation of Russian immigrants in Israel: Between integration and socio-cultural retention. Diaspora, 12(1), 39-66. doi:10.1353/dsp.2011.0043

Remennick, L., \& Prashizky, A. (2018). Generation 1.5 of Russian Israelis: Integrated but distinct. Journal of Modern Jewish Studies.

Roberge, M. (2002). California's generation 1.5 immigrants: What experiences, characteristics and needs do they bring to our English classes? The CATESOL Journal, 14(1), 107-129.

Sabar Ben-Yehoshua, N. (2016). Hakdama [Introduction]. In N. Sabar Ben-Yehushua (Ed.), Mesorot ve'zramim bamechkar ha'echutani [Traditions and streams in qualitative research] (pp. 11-15). MOFET Institute (Hebrew).

Saka, Y., Walsh, S., Bensimon, M., Cohen-Goldner, S., \& Ronel, N. (2012). Tahlichei ezra atzmit ve'ha'atzama ishit [Self-help processes and personal empowerment]. Bar-Ilan University (Hebrew).

Shalom, S. (2012). Mi'Sinai le'Ethiopia [From Sinai to Ethiopia]. Yediot Aharonot (Hebrew).

Sharaby, R. (2002). Syncretism ve'histaglut [Syncretism and adjustment]. Zerichover (Hebrew).

Sharaby, R. (2009). Hag ha'Mimouna be'Israel: Me'haperipheriya la'mercaz [The Mimouna Holiday: From the periphery to the center]. Hakibbutz Hameuchad and Yad Ben Zvi (Hebrew).

Sharaby, R. (2015). Immigration and entry into the cultural mainstream. International Migration, 53(4), 155-175.

Sharaby, R. (2017). The renewal of an ethnic tradition and its role in shaping the Kurds immigrants' identity. Journal of Immigrants \& Minorities, 35(2), 129-147.

Sharaby, R. (2018). "We want integration but such that shows our part": Ethnic activism among immigrants' political-social leadership. Advances in Social Sciences Research Journal, 5(12), 154-172.

Sharaby, R. (2019). Preserving the boundaries of an immigrants' ethnic tradition via a ritual system. Journal of Ritual Studies, 33(2), 31-49.

Sharaby, R. (2020a). Reflection of the spiritual leadership's status in a transfer of ritual process. International Journal of Social Science Studies, 8(3), 105-115.

Sharaby, R. (2020b). Identity consolidation of Ethiopian youth via an ethnic celebration. International Journal of Education Humanities and Social Science, 3(4), 15-30.

Sharaby, R. (2020c). Zehut ve'etniyut be'chagigot ha'ruzh-ba shel Yehudei Iran be'Israel [Identity and ethnic and in Ruz-e-Bah celebrations of Iranian Jews in Israel]. Journal for the Study of Communities in Iran, Bukhara and Afghanistan-IBA, 12, 12-35 (Hebrew).

Sharaby, R., \& Kaplan, A. (2014). Kemo bubot be'halon ra'ava [Like mannequins in a shop window]. Resling (Hebrew). 
Shmuel, N. (2017). Mishpacha ve'masoret bema'avar ben trabuti [Family and tradition in an intercultural transition] Doctoral dissertation, The Hebrew University (Hebrew).

Sivan, L., \& Fredo, Z. (2002). Syncretism behag ha 'Sigd [Syncretism in the Sigd holiday]. Seminar paper under the supervision of Author, Seminar: Syncretism, Ashkelon Academic College (Israel).

Slootman, M. (2019). Ethnic-minority climbers: Evaluating "minority cultures of mobility" as a lens to study Dutch minority student organizations. Ethnic and Racial Studies, 42(5), 838856.

Spector, S. (2005). Operation Solomon. Oxford University Press.

Steering Center for Ethiopian Immigrants in the Education System. (2004). Sikum pe'iluyot ben 2000-2004 [Summary of activities from 2000-2004]. Ministry of Education (Hebrew).

Stewart, C., \& Shaw, R. (1994). Introduction. In C. Stewart \& R. Shaw (Eds.), Syncretism / Anti Syncretism (pp. 1-26). Routledge.

Stroup, D. (2017). Boundaries of belief: Religious practices and the construction of ethnic identity in Hui Muslim communities. Ethnic \& Racial Studies, 40(6), 988-1006.

Strunc, A. (2020). Editorial: Are They Listening? Policymakers and Their Role in Public Education. Research in Educational Policy and Management,2(1), i-iii. https://doi.org/10.46303/repam.02.01.ed

Tarman, B., \& Gürel, D. (2017). Awareness of social studies teacher candidates on refugees in Turkey. Journal of Social Studies Research, 41(3), 183-193. 10.1016/j.jssr.2016.11.001

van Mannen, J. (2011). Tales from the field: On writing ethnography. Chicago University Press.

Vertovec, S. (2001). Transnationalism and identity. Journal of Ethnic and Migration Studies, 27(4), 573-582. https://doi.org/10.1080/13691830120090386

Walter, H., Kampling, R., Levine, A., Markschies, C., Schäfer, P., \& Thurner, M. (2019). Encyclopedia of Jewish-Christian Relations Online. De Gruyter.

Weber, M. (1979). Al ha'charisma ve'beniyat ha'mosadot [On charisma and the construction of institutions]. The Hebrew University (Hebrew).

Yigit, M. F., \& Tarman, B. (2016). How do different ethnicities approach to the education system and differences in Turkey? Italian Sociological Review, 6(3), 339-353. 10.13136/isr.v6i3.119

Yuval-Davis, N., Anthias, F., \& Kofman, E. (2005). Secure borders and safe haven and the gendered politics of belonging: Beyond social cohesion. Ethnic \& Race Studies, 28(3), 513535 .

Zhang, B., Druijven, P., \& Strijker, D. (2018). A tale of three cities: Negotiating ethnic identity and acculturation in northwest China. Journal of Cultural Geography, 35(1), 44-74. https://doi.org/10.1080/08873631.2017.1375779

Zhou, M., \& Bankston, C. (1998). Growing up American: challenge confronting immigrant children and children of immigrants. Russell Sage.

\section{Notes on Contributors}

Rachel Sharaby is head of the Sociology and Anthropology Department, at the Ashkelon Academic College. She is Associate editor of Hagira - Israel Journal of Migration (English and Hebrew), together with Sergio Della Pergola, the Editor-in-Chief. Her studies discuss ethnicism, immigration, identity, gender, intercultural encounters and syncretism. Her latest book is Dynamics of Gender Borders (with Prof. Silvia Fogiel-Bijaoui), Walter de Gruyter, Berlin/Boston \& Hebrew University Magnes Press (2017). 